\title{
AN ASYMMETRIC LIQUID CRYSTAL POLYMER BASED FRACTAL SLOTTED UWB MONOPOLE ANTENNA WITH NOTCH BAND CHARACTERISTICS
}

\author{
B.T.P. Madhav, D.S. Ram Kiran, V. Alekhya, M. Vani, T. Avinash \\ and P. Sreekanth, T. Anilkumar \\ Department of ECE, K L University,Vaddeswaram, AP, India \\ E-mail: btpmadhav@kluniversity.in
}

\begin{abstract}
An improvement of the fractal antenna is made to enhance its gain and bandwidth. In this paper, a relative study of the fractal antenna which is excited by the CPW is done. The antenna that we proposed was designed and simulated using HFSS. Using the fractal concept and CPW-feed technique the compact size and the ultra wideband impedance matching is obtained. The final dimensions of the designed antenna measure $36.4 \mathrm{~mm} \times 40 \mathrm{~mm} \times 1.53 \mathrm{~mm}$. A low-cost FR-4 substrate is used in this design. The UWB characteristic of the antenna ranges from $3.137 \mathrm{GHz}-11.4332 \mathrm{GHz}$ with a notch band from $3.7716 \mathrm{GHz}$ to $4.07 \mathrm{GHz}$. The designed antenna is mainly used for the UWB pulse based trans-receiving applications.
\end{abstract}

Keywords: Asymmetric, Antenna, Fractal, Monopole, Liquid Crystal Polymer.

(C) RASĀYAN. All rights reserved

\section{INTRODUCTION}

An antenna which is a primal component in wireless communication is a specialized transducer that converts the applied electrical power to RF waves or vice versa. As the technology is advancing continuously, urging for the enhancement, there are a number of possibilities for applying this technology in different fields. So, to meet these demands various antenna configurations are designed and improved. Therefore, an antenna whose response differs from the regular antenna with a structure that has an increased area capable of transmitting and receiving RF signals within its volume, and operates with a better performance at various frequencies. One such configuration with a self-similar structure, smaller in size and multi-band or wideband traits is a fractal antenna. ${ }^{1}$ An antenna with the modified ground plane (T-shape) improves the high-frequency radiation performance and the impedance bandwidth. The antenna was constructed with the total dimensions of $59 \mathrm{~mm} \times 90 \mathrm{~mm} \times 1.6 \mathrm{~mm} .^{2}$ Application of fractal antenna with ultra-wideband frequency range plays a vital role. A compact hexagonal Sierpinski fractal antenna with a coplanar wave guide feeding works for super wide band application is designed for the bandwidth ratio of $11: 1 .^{3}$ Some of the advantages of CPW feed is the structural strength, low inductance. ${ }^{4}$ Most of the researchers concentrate on the reduction of size while the others in producing the multi band characteristics. A CPW feed antenna with the circular patch is proposed for Ground Penetrating Radar Applications designed on Rogers RO3010 substrate having permittivity 1.2 operating in 1.1 to $5.5 \mathrm{GHz}$ band. ${ }^{5}$ A flower-shaped microstrip antenna with modified version of the circular patch is reported $^{6}$ is operating in $2.2-10.6 \mathrm{GHz}$ radiates with Omni-directional radiation. With a semi-circular shaped patch ${ }^{7}$ experimentation is carried on microstrip line feed and CPW feeding methods in which the CPW feed gives wide impedance bandwidth than the microstrip line configuration. An Hour-glass shaped monopole antenna with asymmetrical CPW feed demonstrated ${ }^{8}$, exhibits the UWB characteristics with an impedance bandwidth of $134 \%$. The Cantor set fractal antenna fed with coplanar waveguide feed is designed ${ }^{9}$, possesses slots which create the lower resonant frequencies and thus providing the miniaturized designs. A fractal antenna with elliptical-shaped patch fed with CPW feed reports the UWB performance with high impedance bandwidth. ${ }^{10}$ Multiple operating band 
functionality is achieved by modifying the inner fractal patch and fed with CPW feed and supports for several mobile communication systems ${ }^{11}$. The Koch fractal concept was used ${ }^{12}$ for a log periodic antenna for achieving Ultra-High Frequency radiation characteristics. The achievement of UWB characteristics along with avoiding the antenna operating characteristics for a specific band is still a challenging task and the current research is focusing the same with some geometrical implementations.

In this paper, a new circular fractal antenna with notched-band is presented for the UWB system applications. Changing the length and width of the slot the notched band is tuned. The antenna has advantages of low profile, compact size, easy fabrication, low manufacturing cost and sufficiency of the very small ground plane for integration with compact UWB systems. The performance of the proposed antenna is characterized in term of return loss, gain and radiation pattern.

\section{Liquid Crystal Polymer Substrate}

LCP is one of the flexible and conformal substrates in the market with numerous advantages over conventional dielectric materials. ${ }^{13-19}$ The advantages of LCP are

- LCP is having excellent high-frequency electrical properties, stable $\varepsilon_{\mathrm{r}}$ and low loss tangent 0.0020.004 for frequency $<35 \mathrm{GHz}$.

- Quasi-hermetic

- Low coefficient of thermal expansion(CTE)

- Recyclable

- Cost is less

- Naturally Non-flammable(Environmentally Friendly)

- Flexible

- Multilayer all LCP laminations capabilities to create multilayer LCP RF modules

- Relatively low lamination processing temperature $\left(=2850^{\circ} \mathrm{c}\right)$

- Low dielectric constant for use as an efficient antenna substrate.

The LCP material is used in this work along with FR4 substrate and its performance characteristics are analyzed and presented.

\section{Antenna Geometry}

The solid circular monopole antenna has been designed on a low-cost FR-4 substrate with a thickness of $1.53 \mathrm{~mm}$ and $\varepsilon_{\mathrm{r}}=4.4$ and on LCP substrate with dielectric constant 2.9. Initially, the FR4 substrate material based model is implemented with CPW feeding technique in this design. The radiating element and the feed are printed on the top side of the substrate. The zeroth iteration is the circle constructed with the radius of $18.5 \mathrm{~mm}$. A square patch of dimensions $17.5 \times 17.5 \mathrm{~mm}^{2}$ is considered and inscribed on the zeroth iteration. Further, the first iteration is obtained by removing the square shaped portion from the circular patch. The obtained area should be united with the zeroth iteration. Again, a square patch of $12.05 \times 12.05 \mathrm{~mm}^{2}$ is engraved on the circle of diameter $13.05 \mathrm{~mm}$. Hence a second iteration is obtained by subtracting the square from the circular patch. The obtained area should be united with the first iteration. Further, the third iteration is designed by engraving a square patch of dimensions $8.05 \times 8.05 \mathrm{~mm}^{2}$ on the circle of radius $9.05 \mathrm{~mm}$. Here the square patch is subtracted from the circular patch and is united with the second iteration. At last the final or the fourth iteration is obtained by inscribing a square patch of $4.525 \times 4.525 \mathrm{~mm}^{2}$ on the circle of radius $6.4 \mathrm{~mm}$. Now the square patch is subtracted from the circle and united with the third iteration to get the final iteration. This procedure can be continued up to infinite iterations which are practically impossible, so the design is limited up to the fourth iteration.CPW has the signal and the ground conductors on the same layer. The rectangular portion of the patch separates the two ground planes, having dimensions $20.4 \times 18.00 \mathrm{~mm}^{2}$ and $16.4 \times 18.00 \mathrm{~mm}^{2}$ which lie on the either side respectively form the asymmetric feed configuration. A U-shaped slot as shown in Fig.-2 with each rectangular branch of length $11.6 \mathrm{~mm}$, width of $0.4 \mathrm{~mm}$ and with a gap of $0.4 \mathrm{~mm}$ between the two rectangular branches is inserted in the $50 \Omega$ feed line of the coplanar wave guide to obtain the notched band frequency band. The effective length of the slot defines the resonant frequency of the notched band. 
Four similar slots are made for every iteration and totally 16 slots were made for four iteration. For every $i^{\text {th }}$ iteration a rectangle of ' $y \mathrm{x} y \mathrm{~mm}^{2}$ dimensions was taken and inserted in a circle of ' $\mathrm{k} \mathrm{mm}$ ' radius and removed from it to get the slot. These slots are united with their respective iteration.

Table 1: Geometrical Parameters of Antenna

\begin{tabular}{l|l|l|l|l|l|l|l|l|l|l}
\hline Parameter & $\mathrm{L}$ & $\mathrm{L}_{1}$ & $\mathrm{~W}$ & $\mathrm{r} 1$ & $\mathrm{r} 2$ & $\mathrm{r} 3$ & $\mathrm{r} 4$ & $\mathrm{~d}_{1}$ & $\mathrm{~d}_{2}$ & $\mathrm{~h}$ \\
\hline Value in $\mathrm{mm}$ & 40 & 18 & 36.4 & 18.05 & 13.05 & 9.05 & 6.4 & 0.4 & 0.4 & 11 \\
\hline
\end{tabular}

Table 2: Dimensions of Iterative fractal slots

\begin{tabular}{c|c|c|c|c}
\hline ITERATION (i) & 1 & 2 & 3 & 4 \\
\hline Radius of circular slot('k' mm) & 0.5 & 0.4 & 0.25 & 0.16 \\
\hline Side length of Square ('y'mm) & 0.4 & 0.3 & 0.15 & 0.12 \\
\hline
\end{tabular}

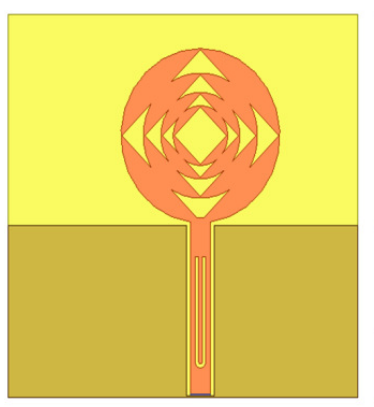

(a)

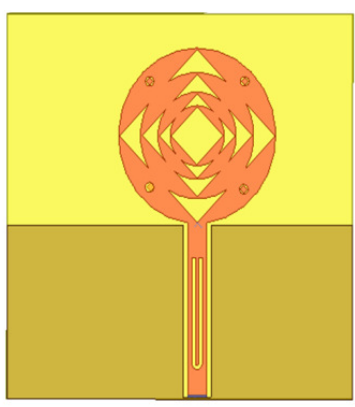

(b)

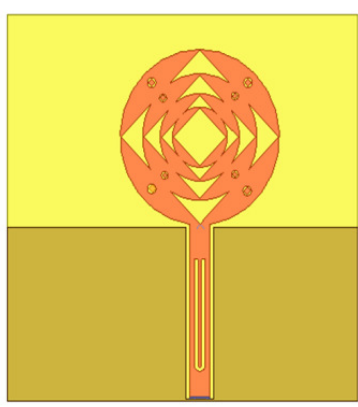

(c)

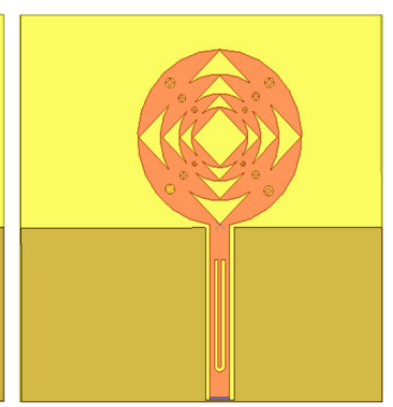

(d)

Fig.-1: (a) Basic Antenna (b) 1st Iteration (c) 2nd Iteration (d) 3rd Iteration

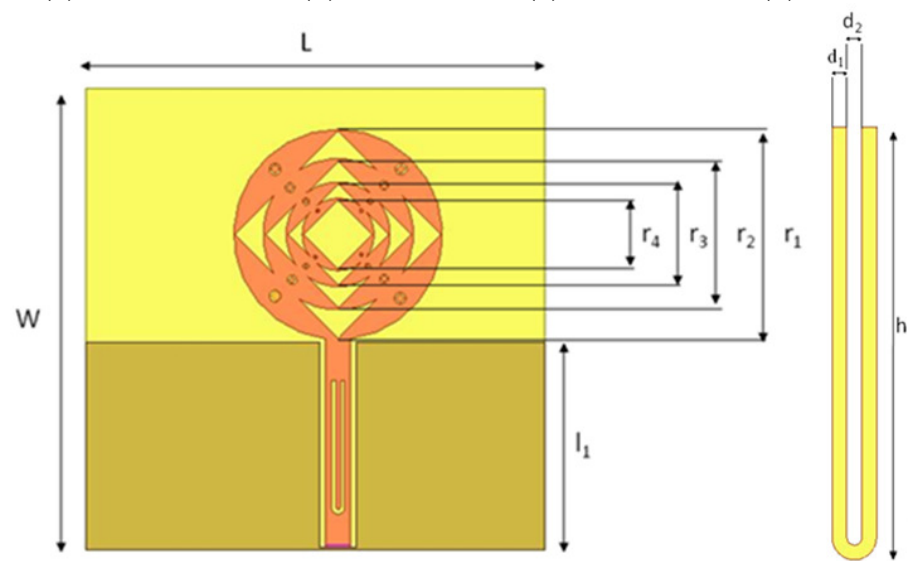

Fig.-2: CPW Feed Square Fractal Slotted UWB Monopole Antenna

\section{Simulation Results}

The proposed design iterations modeled and simulated using ANSYS HFSS 17 simulation tool and presented the various antenna parameters such as return loss $\left(S_{11}\right)$, peak gain across the operating band, radiated field distributions, and surface field densities to analyze the antenna electromagnetic behavior.

The $S_{11}$ of four iterations along with the basic designed antenna structure are shown in Fig.-3. It is observed that for this antenna, ultra wide band i.e. from $3.1370 \mathrm{GHz}-11.4332 \mathrm{GHz}$ for basic has been improved to a bandwidth ranging from $3.1158 \mathrm{GHz}-11.9452 \mathrm{GHz}$. This shows that the impedance band width has got increased on increasing the number of iterative fractal slots. The notch band or the rejection band has also been improved from basic to the final iteration which is obtained at the resonant frequency of $4.3 \mathrm{GHz}$. It is observed that antenna is well matched to a large range of frequencies obtaining the ultra- 
wide band range. The $-10 \mathrm{~dB}$ impedance bandwidth and occurrence of notch bands, which are computed from the return loss plot is shown in Table-3.

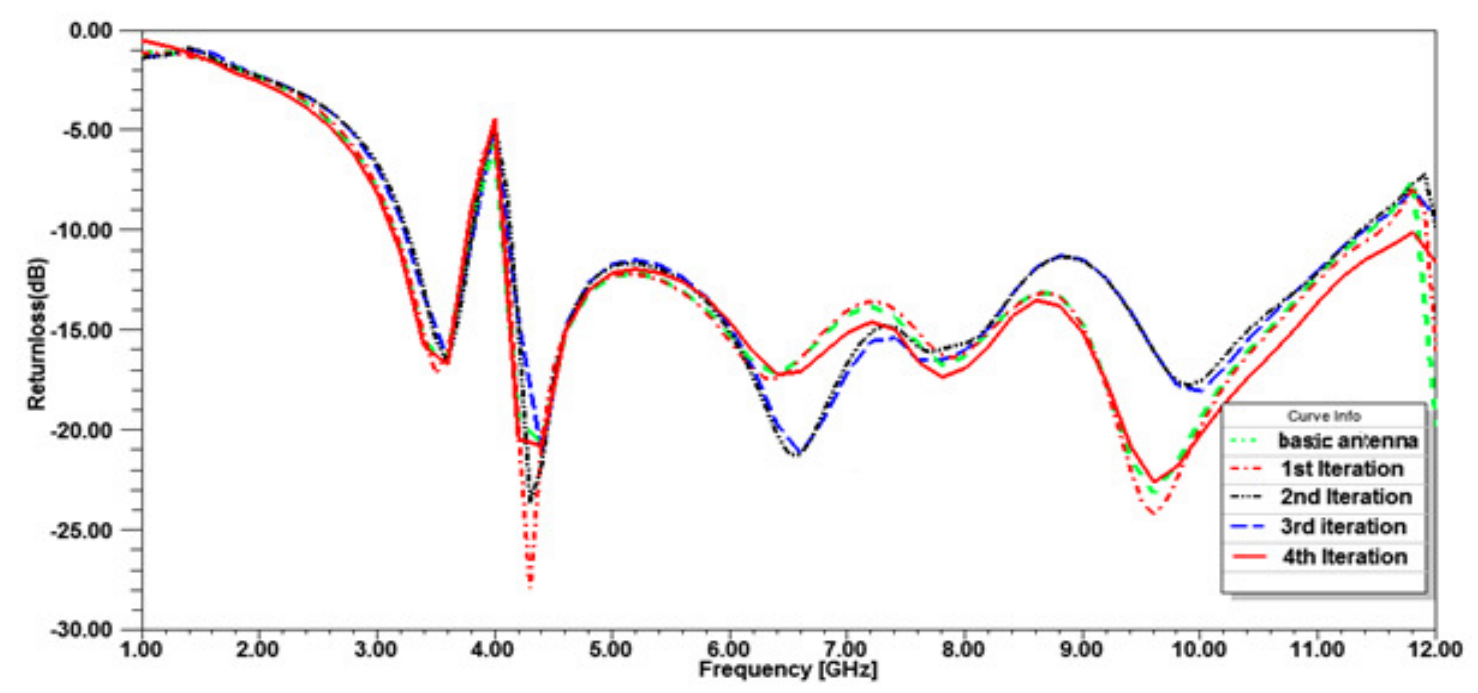

Fig.-3: Return loss characteristics of proposed fractal slotted antenna iterations

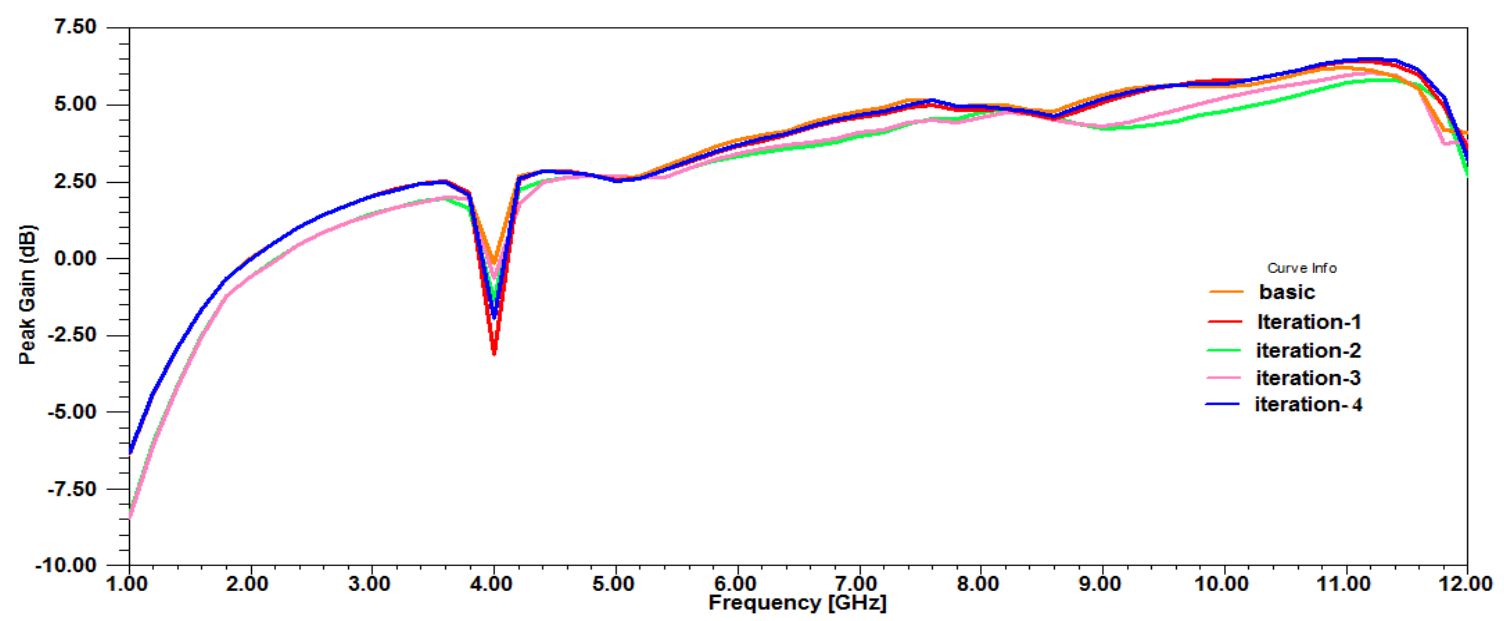

Fig.-3: Peak gain vs frequency characteristics of fractal slotted CPW antenna iterations

Table-3: Operating and notch band characteristics of proposed fractal slotted CPW antenna with several iterations

\begin{tabular}{l|l|l|l|l}
\hline \multirow{2}{*}{ Number Iterations } & \multicolumn{2}{|c|}{$\begin{array}{c}\text { Operating Bandwidth (GHz) } \\
\text { (excluding notch band) }\end{array}$} & \multicolumn{2}{c}{ Notch band (in GHz) } \\
\cline { 2 - 5 } & Start & Stop & Start & Stop \\
\hline Zeroth (basic) & 3.1370 & 11.4332 & 3.7868 & 4.0625 \\
\hline First Iteration & 3.1523 & 11.5328 & 3.7807 & 4.0820 \\
\hline Second Iteration & 3.2509 & 11.3565 & 3.8117 & 4.1306 \\
\hline Third Iteration & 3.2090 & 11.3862 & 3.8199 & 4.1080 \\
\hline Fourth Iteration & 3.1158 & 11.9452 & 3.7716 & 4.0700 \\
\hline
\end{tabular}

The peak gain for four iterations along with the basic design antenna structure is shown in figure 3. Their comparison in the terms of the peak gain versus frequency plots is shown above and listed in the below 
table 3. For the final iteration, the gain is measured to be $6.4865 \mathrm{~dB}$ and for which the basic antenna is found to be $6.1984 \mathrm{~dB}$. The gain in the notch band transformed to $-1.9508 \mathrm{~dB}$ for the fourth iteration from $0.1902 \mathrm{~dB}$ for the basic antenna.

Table-4: Maximum and Average antenna gain values for operating band and notch bands

\begin{tabular}{l|l|l|l}
\hline \multirow{2}{*}{\multicolumn{1}{c|}{ Number Iterations }} & \multicolumn{2}{|c|}{$\begin{array}{c}\text { Peak gain in operating band } \\
\text { (in dB) }\end{array}$} & $\begin{array}{l}\text { Peak Gain in the Notch } \\
\text { Band (in dB) }\end{array}$ \\
\cline { 2 - 3 } & \multicolumn{1}{|c|}{ Max } & Avg & \\
\hline Zeroth (basic) & 6.1984 & 4.2022 & -0.1902 \\
\hline First Iteration & 6.3840 & 4.1701 & -3.1301 \\
\hline Second Iteration & 5.7872 & 3.7297 & -1.3702 \\
\hline Third Iteration & 6.0057 & 3.8429 & -0.6481 \\
\hline Fourth Iteration & 6.4865 & 4.2355 & -1.9508 \\
\hline
\end{tabular}

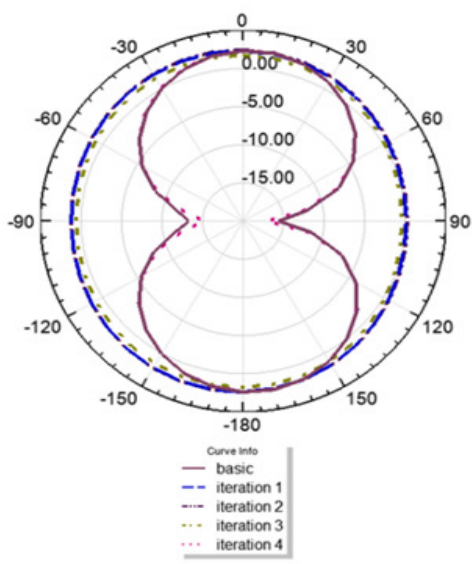

(a)

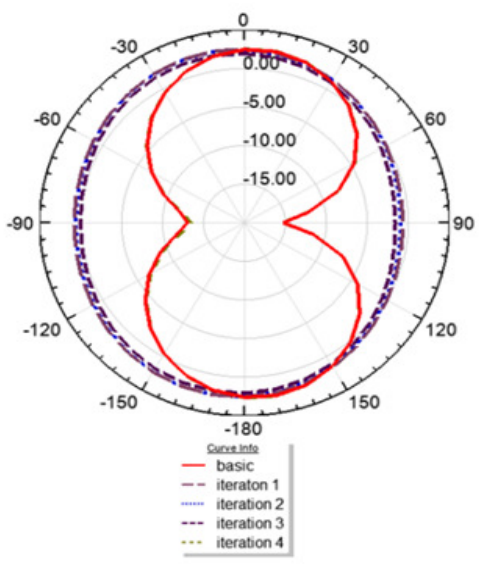

(b)

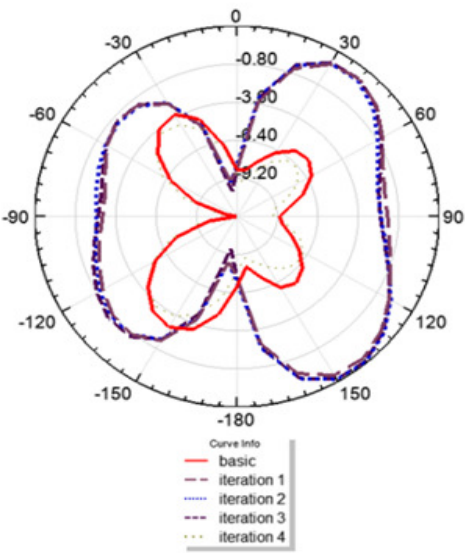

(c)

Fig.-4: Radiation pattern in E-plane (a) at $3.6 \mathrm{GHz}$ (b) at $4.3 \mathrm{GHz}$ (c) at $8 \mathrm{GHz}$

The radiation pattern in E-plane has been plotted at frequencies $3.6 \mathrm{GHz}, 4.3 \mathrm{GHz}$, and $8 \mathrm{GHz}$ for all the iterations and is shown in the Fig.-4. It is observed from Figures- 4(a) and 4(b) that the radiation pattern for the basic antenna and the fourth iterative is bi-directional and the radiation pattern is Omni-directional for the iterations-1,2 and 3 respectively. From the Fig 4(c), the radiation pattern for the basic antenna and the fourth iterative is directed towards angles $-35^{\circ},-140^{\circ}, 50^{\circ}, 140^{\circ}$ in the E-plane and the radiation pattern is directed towards angles $-45^{0},-135^{0}, 35^{0}, 140^{\circ}$ in the elevation plane for the iterations-1,2 and 3 .

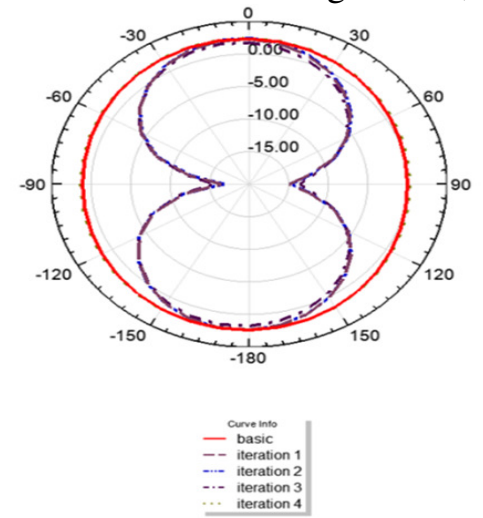

(a)
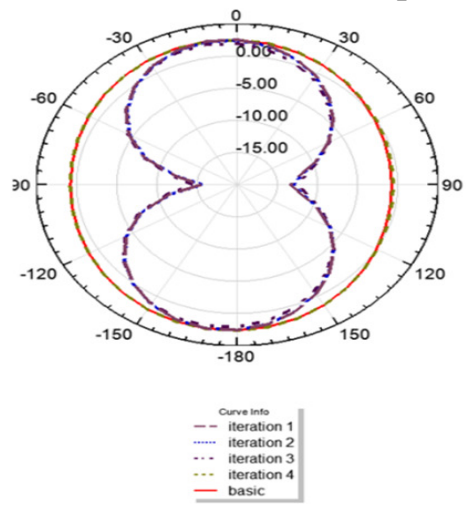

(b)

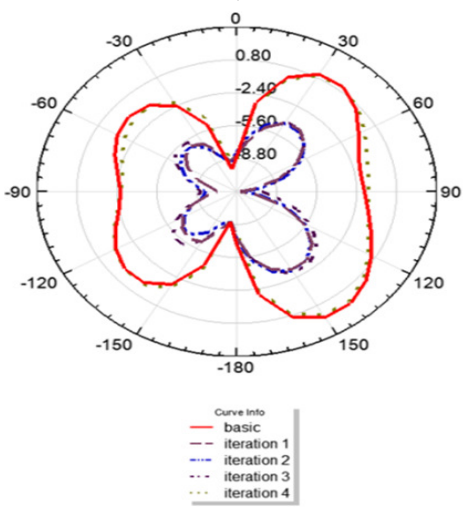

(c)

Fig.-5: Radiation pattern in $\mathrm{H}$-plane (a) at $3.6 \mathrm{GHz}$ (b) at $4.3 \mathrm{GHz}$ (c) at $8 \mathrm{GHz}$ 
The radiation pattern in $\mathrm{H}$-plane has been plotted at frequencies $3.6 \mathrm{GHz}, 4.3 \mathrm{GHz}$, and $8 \mathrm{GHz}$ for all the iterations and is shown in the Fig.-5. It is observed from Figures- 5(a) and 5(b) that the radiation pattern for the basic antenna and the fourth iterative is Omni-directional and the radiation pattern is bidirectional for the first three iterations. Also from the Fig.-5(c), the radiation pattern for the basic antenna and the fourth iterative is directed towards angles $-45^{0},-140^{\circ}, 35^{0}, 145^{\circ}$ in the H-plane and the radiation pattern is directed towards angles $-45^{0},-135^{0}, 35^{\circ}, 140^{\circ}$ for first, second and third iterative designs It can be observed that at higher frequencies the nulls are being occurred in XY plane.

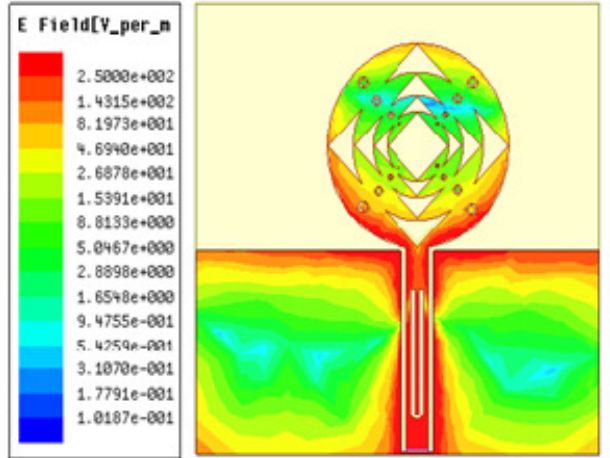

(a)

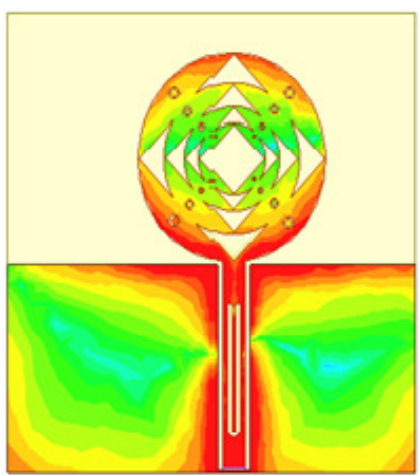

(b)

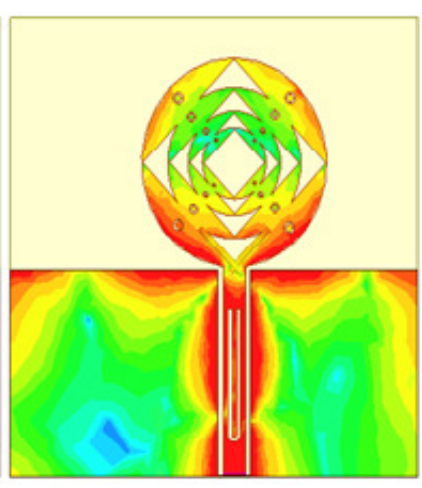

(c)

Fig..-6: Simulated Electric field distributions on proposed fractal slotted CPW antenna

(a) at $3.6 \mathrm{GHz}$, (b) at $4.3 \mathrm{GHz}$, (c)at $8 \mathrm{GHz}$.

From the Fig. 6 it can be observed that for the same phase of excitation the field is more concentrated on the feed line. At $3.6 \mathrm{GHz}$ frequency, the edges of the ground are surrounded by greater field density and as the frequency increases the near to null field density can be seen which is evident from Fig.-6(b) and Fig.-6(c). Moreover, the minimum field is obtained at the mid region of the ground conductors etched either side of the signal conductor. Field strength composing of multiple electrical lengths can be seen at high frequency.
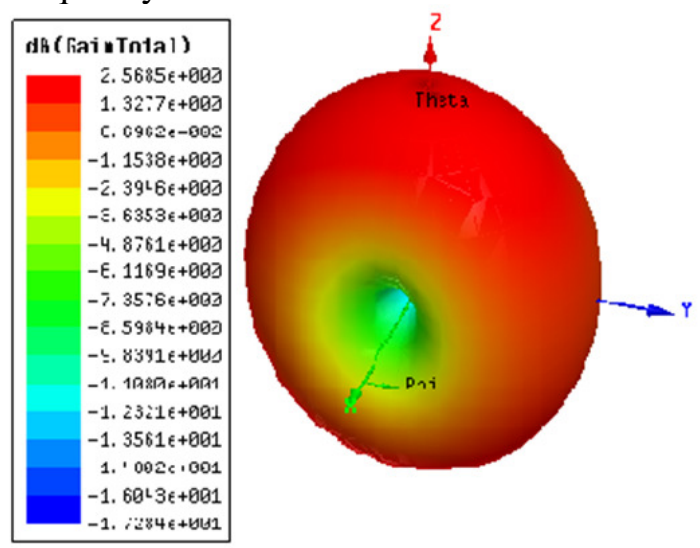

(a)

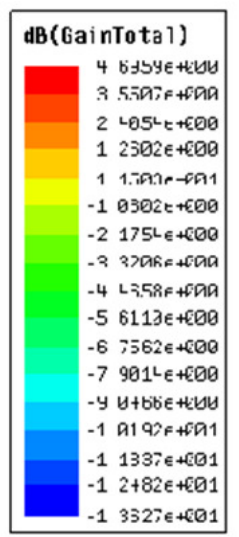

(b)

Fig.-7: Three-dimensional far-field patterns (a) at $4.38 \mathrm{GHz}$ (b) at $8 \mathrm{GHz}$

The three-dimensional radiation patterns are presented in terms of logarithmic gain in Fig. -7 and are plotted for two frequencies. A gain of $4.6959 \mathrm{~dB}$ at $8 \mathrm{GHz}$ with bi-directional radiation towards the orientation of radiating patch. For the notch band, the gain value is decreased and observed the gain as $2.783 \mathrm{~dB}$ at frequency $4.38 \mathrm{GHz}$ which provides radiation with omnidirectional characteristics.

The proposed antenna is also analyzed with the LCP substrate material named Rogers Ultralam 1300 with a relative permittivity of 3 and loss tangent of 0.003 . The proposed antenna with FR-4 dielectric is operating in the band ranging from $3.132 \mathrm{GHz}$ to $14.54 \mathrm{GHz}$ with the occurrence of notch bands from 3.8 
$\mathrm{GHz}$ to $4.05 \mathrm{GHz}$ with notch center at $3.94 \mathrm{GHz}$ and $11.44 \mathrm{GHz}$ to $11.84 \mathrm{GHz}$ with notch center frequency at $11.76 \mathrm{GHz}$. While simulating on the LCP substrate, the proposed design operates from $3.4011 \mathrm{GHz}$ extending beyond $15 \mathrm{GHz}$, notching the bands from $4.2-4.58 \mathrm{GHz}$ with notch center from 4.46 GHz and another notch band at $12.4-13.66 \mathrm{GHz}$ with a maximum peak in notch band is obtained at $13.58 \mathrm{GHz}$. It can be observed from the plot that the design of the patch antenna on the LCP material improves the notch band performance which can be inferred from the Fig.-8. in which for LCP material the notch center frequency has attained 15.10:1 and 4.69:1 VSWR values.

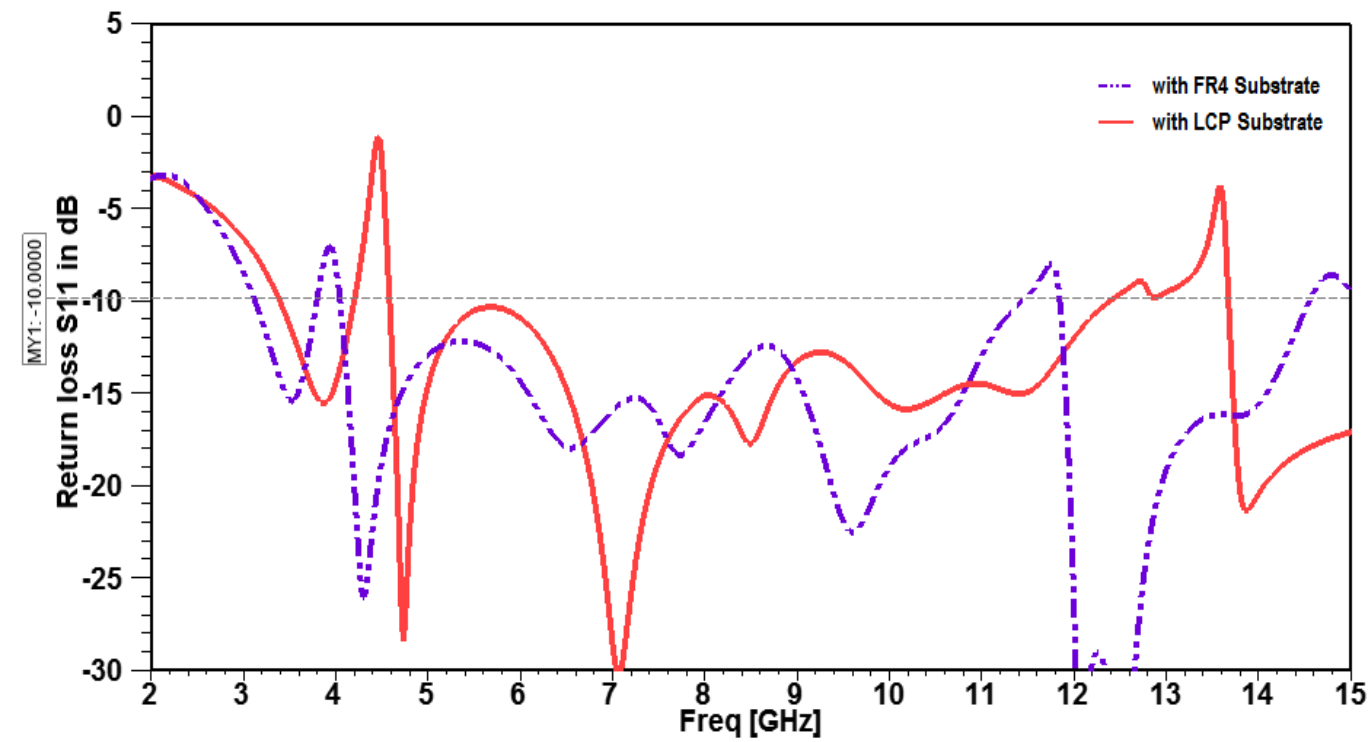

(a)

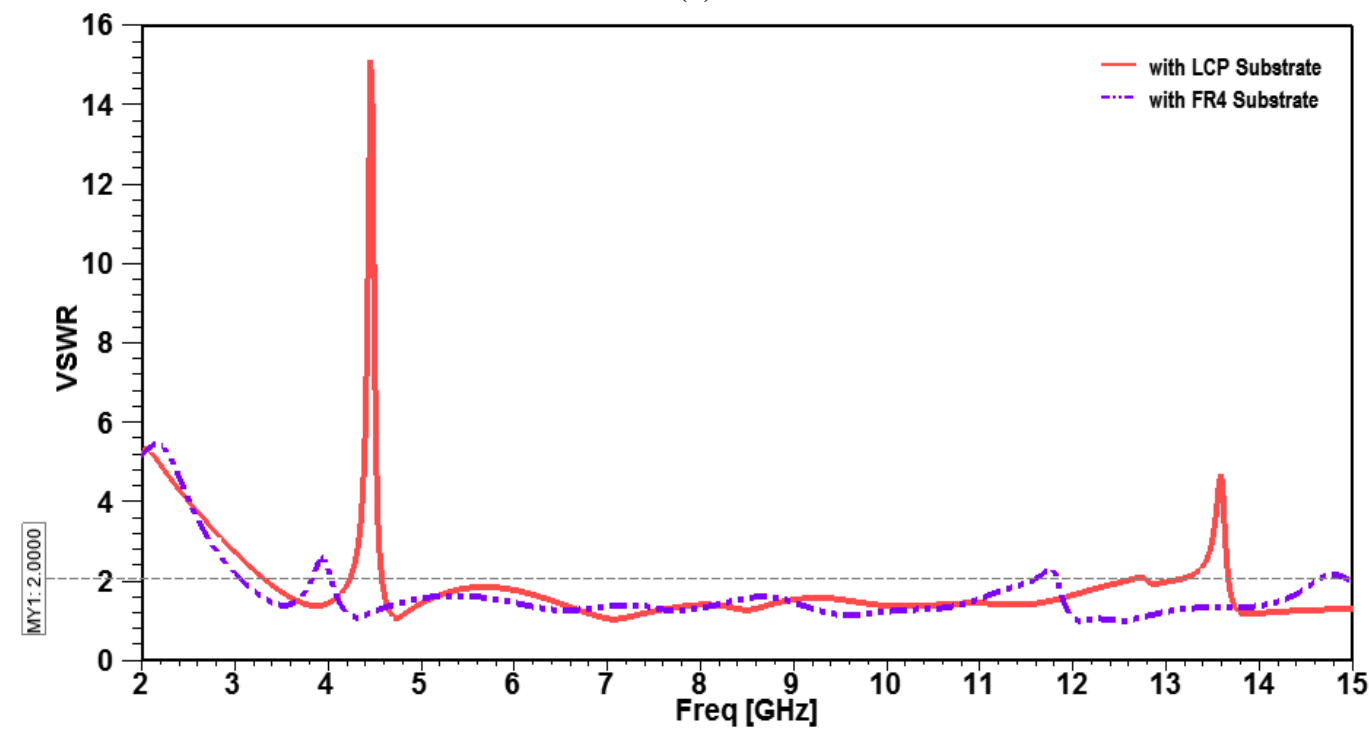

(b)

Fig.-8 (a) Return loss and (b) VSWR performance of the proposed antenna with FR4 and LCP substrate material

The peak gains vs. frequency comparative characteristics are shown in Fig.-9 shows the improvement in the antenna's gain performance. Statistically, the maximum gain values are obtained as $6.5541 \mathrm{~dB}$ for an antenna with LCP material and $6.2816 \mathrm{~dB}$ for the FR4 substrate. The average gain also improved when using the LCP substrate and it is found to be $4.9568 \mathrm{~dB}$ and for FR4 substrate it is noted as $4.5516 \mathrm{~dB}$ with the percentage improvement of $8.9 \%$. 


\section{CONCLUSION}

In this paper, a symmetric CPW antenna with the circular patch is proposed. The patch is slotted with square fractals and the U-shaped slot is provided in the signal conductor of the feed line notches the band 3.7716 to $4.0700 \mathrm{GHz}$ that possessing the interfering Wi-MAX bands. With the incorporation of miniaturized iterative fractal slots on the radiating element, the improvement of $3 \%$ in impedance bandwidth from $113.8 \%$ to $117.24 \%$ has been attained when compared with the base antenna. Moreover, the enhancement of $4.64 \%$ in antenna maximum gain from $6.1984 \mathrm{~dB}$ to $6.4865 \mathrm{~dB}$ is obtained when compared to zeroth iteration and fourth iteration designs. The study of antenna geometry is performed using the liquid crystal polymer substrate which shows the enhanced bandwidth characteristics. When considering the extended frequency sweep up to $15 \mathrm{GHz}$, the proposed antenna with LCP material exhibits an improvement in a gain of $8.9 \%$ compared to the FR4 material.

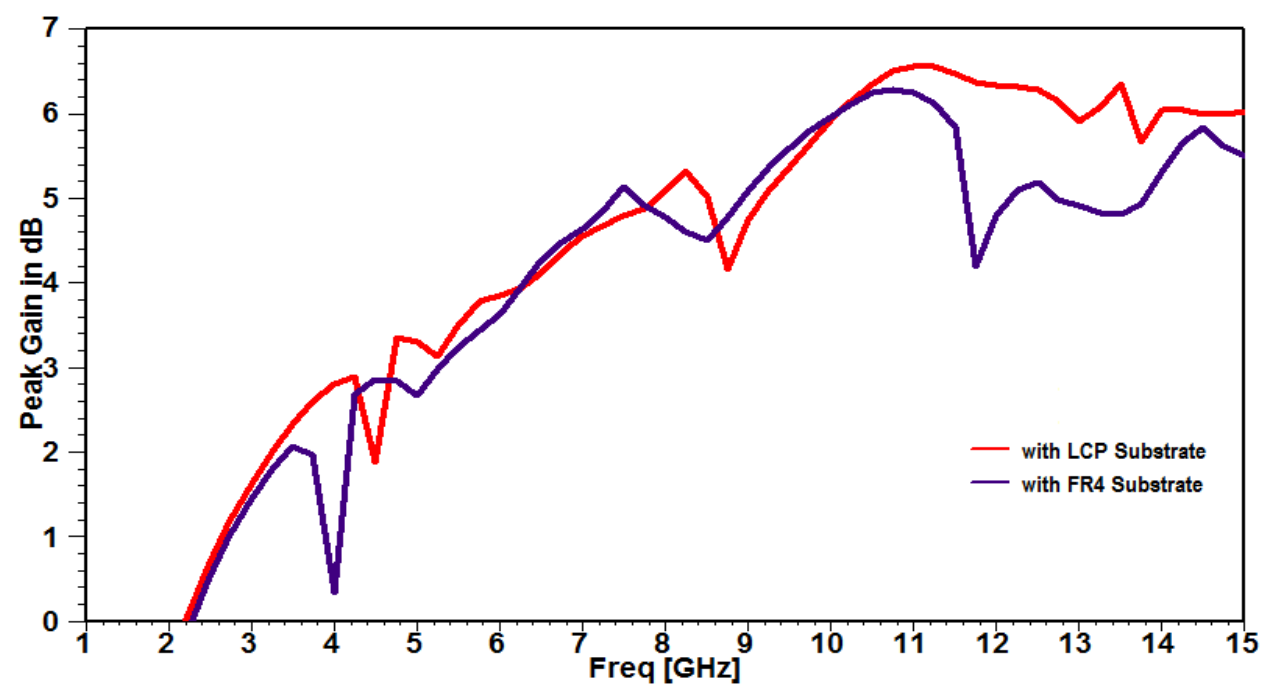

Fig.-9: Peak gain Vs Frequency Characteristics of proposed antenna with FR4 and LCP substrate material

\section{ACKNOWLEDGEMENT}

The authors deeply express their gratitude to Antennas \&Liquid crystals Research Centre, Department of ECE, K L University for their encouragement during this work. Further, Madhav would like to express his gratitude to DST through grant ECR/2016/000569 and FIST grant SR/FST/ETI-316/2012.

\section{REFERENCES}

1. S. Singhal and A. K. Singh, IET Microwaves, Antennas \& Propagation, 10 (5), 1(2016).

2. C. Mahatthanajatuphat, S. Saleekaw, P. Akkaraekthalin, and M. Krairiksh, Progress In Electromagnetics Research, 89, 57 (2009).

3. L.K. Kim, J. G. Yook, and H. K. Park, Microwave and Optical Technology Letters, 34(1), 5(2002)

4. J. P. de Villiers and J. P. Jacobs, Progress In Electromagnetic Research, 98, 233 (2009).

5. $\quad$ M.N.A.Karim et al., Lecture Notes in Electrical Engineering, 344, 59(2015).

6. $\quad$ S.R. Patre and S.P. Singh, Microw. Opt. Technol. Lett., 57, 2908 (2015).

7. T.M. Telsang and A.B. Kakade, Microw. Opt. Technol. Lett., 56(2), 362(2014).

8. Sarthak Singhal and Amit Kumar Singh, Wireless Personal Communications, 94(3), 1685 (2016).

9. A. Reha, A. El Amri, O. Benhmammouch, Said A. Oulad, Lecture Notes in Electrical Engineering, 366 (2), 171 (2015).

10. S. Maiti, N. Pani, T.R. Devi, A. Datta, Advances in Intelligent Systems and Computing, 309, 229 (2015).

11. C. Mahatthanajatuphat, P. Akkaraekthalin, S. Saleekaw, and M. Krairiksh, Progress In Electromagnetics Research, 95(2), 59 (2009). 
12. M. N. A Karim, M. K. Abd Rahim, H. A. Majid, O. B. Ayop, M. Abu, and F. Zubir, Progress In Electromagnetics Research, 100, 201 (2010).

13. B. T. P. Madhav, V.G.K.M. Pisipati, K. V. L. Bhavani, P. Sreekanth, P. Rakesh Kumar, Journal of Theoretical and Applied Information Technology, 18(1), 62(2010).

14. B. T. P. Madhav, V.G.K.M. Pisipati, Habibulla Khan, V.G.N.S. Prasad, K.S.N. Murty, Journal of Theoretical and Applied Information Technology, 20(2), 105 (2010).

15. B. T. P. Madhav, V.G.K.M. Pisipati, N.V.K Ramesh, Habibulla Khan, P. V. Datta Prasad, ARPN Journal of Engineering and Applied Sciences, 6(4), 98(2011).

16. B. T. P. Madhav, V.G.K.M. Pisipati, Habibulla Khan, V.G.N.S. Prasad, K. Praveen Kumar, K.V.L. Bhavani and P.V. Datta Prasad, International Journal of Applied Engineering Research, 6(9), 1099 (2011).

17. B. T. P. Madhav, V.G.K.M. Pisipati1, Habibulla Khan, V.G.N.S Prasad, K. Praveen Kumar, KVL Bhavani and M. Ravi Kumar, Journal of Engineering Science and Technology Review 4 (2), 131(2011).

18. B.T.P. Madhav, V.G. K. M. Pisipati,, D. Madhavi latha and P. V. Dattaprasad, Solid State Phenomena, 181(3), 289 (2012).

19. B. T. P. Madhav, Harish Kaza, Leonardo Electronic Journal of Practices and Technologies, 26(14), 103(2015).

[RJC-1654/2017] 